\title{
Detection of Radio-Frequency Modulated Optical Signals by Two and Three Terminal Microwave Devices
}

\author{
(NASA-TM-100196) DETECTION OF \\ EADIO-FREQUENCY MODULATED OPTICAL SIGNALS BY \\ N $87-29750$ \\ TWO AND THREE TERMINAL MICRONAVE DEVICAS \\ (NASA) $11 \mathrm{p}$ AVail: NTIS HC AO2/MF AU1 Unclas \\ CSCL O9C G3/33 0100032
}

K.B. Bhasin and R.N. Simons

Lewis Research Center

Cleveland, Ohio

and

S. Wojtczuk

Cornell University

Ithaca, New York

Prepared for the

1987 Technical Symposium on Optics, Electro-Optics and Sensors sponsored by the Society of Photo-Optical Instrumentation Engineers Orlando, Florida, May 17-22, 1987

\section{NMSA}




\title{
DETECTION OF RADIO-FREQUENCY MODULATED OPTICAL SIGNALS BY
}

\section{TWO AND THREE TERMINAL MICROWAVE DEVICES}

\author{
K.B. Bhasin and R.N. Simons* \\ National Aeronautics and Space Administration \\ Lewis Research Center \\ Cleveland, Ohio 44135 \\ and \\ S. Wojtczuk \\ School of Electrical Engineering \\ Cornell University \\ Ithaca, New York 14853
}

\section{SUMMARY}

An interdigitated photoconductor (two terminal device) on GaAlAs/GaAs heterostructure was fabricated and tested by an electro-optical sampling technique. Further, the photoresponse of GaAlAs/GaAs HEMT (three terminal device) was obtained by illuminating the device with an optical signal modulated up to $8 \mathrm{GHz}$. Gain-bandwidth product, response time, and noise properties of photoconductor and HEMT devices were obtained. Monolithic integration of these photodetectors with GaAs microwave devices for optically controlled phased array antenna applications is discussed.

\section{INTRODUCTION}

The use of analog and digital fiber optic links to provide RF feed, phase control, amplitude control, and injection locking of oscillators in GaAs MMIC elements for phased array antenna systems is being considered to reduce weight, size, and crosstalk (ref. 1). Such links require transmitters and receivers. For a large array, discrete receivers bonded to GaAs MMIC, will add to the problem rather than provide the solution. However, integrated optical receivers whose structure is compatible with GaAs MMIC and which can be fabricated using standard techniques, will provide small size, single package element.

Experimental studies to optically control GaAs MESFET, have shown that such devices have the potential for optical detectors (refs. 2 to 6) and their structures are compatible with GaAs MMICs. Photoconductors using GaAs MESFET like structures have also been studied (refs. 7 to 8). Interdigitated surface geometrics used in these photoconductors have shown improved optical coupling efficiency and reduced al ignment problems to these devices.

Recently, optical control of HEMT structures (ref. 9) and HEMT photodetectors (refs. 10 and 11) have also been demonstrated. In this paper, HEMT photodetector with interdigitated surface geometries are presented in section III. Detection of RF modulated optical signal by GaAlAs/GaAs HEMT is

\footnotetext{
*National Research Council - NASA Research Associate.
} 
discussed in section IV. Monolithic integration of optical and microwave functions is discussed in section $V$ and, finally, conclusions are presented in section VI.

\section{PHYSICAL MECHANISM}

Fundamentally, the optical response of a microwave device structure is based on photoconductive and photovoltaic effects; the relative contribution depends on the device and experimental parameters. When a microwave device is illuminated, optical absorption takes place in the device substrate material, the active iayer, and the Shottky and ohmic contact materials, thereby increasing the free carrier density of the device due to a photoconduction effect. This is shown in figure 1 . When potential bias between source and drain is applied, a photoconductive current flows.

Photovoltaic effect contributions to the optical response come from the potential barriers created due to gate and intrinsic layer interface, the buffer layer and substrate interface, and intrinsic layer doping density variations. As the applied gate bias controls the effective intrinsic layer thickness, the optical illumination modulates the FET intrinsic layer in a similar manner. The free carriers generated by illumination are collected in the high electric field of a space - charge region (refs. 3 to 12).

\section{INTERDIGITATED HEMT PHOTOCONDUCTOR}

\section{Detector Structure and Fabrication}

The interdigitated HEMT photoconductive detector structure used for fabrication is shown in figure 2. The photoconductor is square with 50- $\mu \mathrm{m}$ sides. The ohmic contact length is $3 \mu \mathrm{m}$, and two different detectors with the gap spaces of 2.5 and $5 \mu \mathrm{m}$ respectively have been fabricated. The vertical HEMT structure (shown in fig. 3) consists of $1.20 \mu \mathrm{m}$ thick undoped GaAs layer, grown by MBE technique on semi-insulating GaAs substrate. A GaAlAs spacer layer of $40 \mathrm{~A}^{\circ}$ thick. is deposited on GaAs layer, followed by $400 \mathrm{~A}^{\circ}$ thick tests, the devices were mounted on and either ribbon bonded or silver epoxied to a modified SMA end launcher of the type used for the microstrip transmission line transition to coax. An $800 \mathrm{~nm}$ GaAlAs laser 32 ps FWHM pulses was used to measure the time domain response of the various detectors. Quantum efficiency measurements were made by comparing the detectors with the discrete GaAs/GaAlAs PIN reference detector.

\section{Experimental Results}

An I-V curve of the detector, a symmetric device, is shown in figure 4. The operation of this device is independent of bias polarity. The initial linear slope of the curve around the origin closely corresponds to the theoretical low field bulk resistance between the ohmic contacts, and is about $10 \Omega$.

The high field saturation is caused by a combination of carrier velocity saturation and channel pinch-off. The slope, and therefore the detector 
resistance at $d c$, is seen in figure 4 to be a function of the bias, starting at a low value of resistance for small bias, with the resistance smoothly increasing until it becomes large at high bias. The responsivity of $4.4 \mathrm{~A} / \mathrm{W}$ was achieved at $800 \mathrm{~nm}$ wavelength.

The measured impulse responses are shown in figure $5(a)$. The area under the response curves of figure $5(a)$ is proportional to quantum efficiency, $(n)$. the number of carriers collected by the external load ( $50 \Omega$ ) divided by the number of incident photons. This definition allows $n$ to be greater than unity in the case of the photoconductor because of the photoconductive gain. The measured $n$ is 41 .

Since the response time is compared to the optical pulse width ( $32 \mathrm{ps}$ ), the output is a good approximation to the detector impulse response and the frequency domain response is determined from the fast fourier transform of the digitized impulse response (fig. 5(b)). The photodetector (with $2.5 \mathrm{~m}$ spacing) has a gain-bandwidth product of $6.82 \mathrm{GHz}$. Further, it also has a high gain of 41 , but suffers from a low effective bandwidth of about $170 \mathrm{MHz}$ (fig. 5 (ref. 6)).

\section{GaAIAS/GaAS HIGH ELECTRON MOBILITY TRANSISTOR}

\section{Experimental Setup}

A low noise AlGaAs/GaAs high electron mobility transistor (MPD-H503, Gould, Inc.) with recessed $\mathrm{Pi}$-gate of length $0.5 \mu \mathrm{m}$ and width $280 \mu \mathrm{m}$, is used for this experiment. For optical illumination an AlGaAs/GaAs laser diode (SL-620 S, Ortel Corp.) with a fiber pigtail, which operates at a wavelength of $0.83 \mu \mathrm{m}$ and has a direct modulation bandwidth of $10 \mathrm{GHz}$ is used. The optical power emitted from the $50 / 125 \mu$ m multimode graded index optical fiber pigtail as measured using a calibrated digital power meter and a photosensor (815. Newport Corp.) is $1.7 \mathrm{nW}$. The tip of the fiber is held at a distance of $1 \mathrm{~mm}$ from the device.

These devices are mounted on a 0.375 by $0.375 \mathrm{in} ., 25 \mathrm{mil}$ thick alumina carrier. The alumina carrier also accommodates a pair of $50 \Omega$ coplanar waveguides (CPW) which serve as the signal input and also output ports. The device gate and drain pads and the source pad are wire bonded to the CPW center strip conductors and the ground plane respectively. The carrier is then mounted in a test fixture (Design Techniques, Inc.) which has two $3.5 \mathrm{~mm}$ coaxial connectors for external connection. The test fixture also has provision for ensuring repeatable pressure contact between the terminals of the CPWs on the carrier and the two $3.5 \mathrm{~mm}$ coaxial connectors on the fixture. A CPW calibration kit consisting of a $50 \Omega$ through, two short circuits, and an open circuit on similar alumina carriers are used for calibrating the HP8510 automatic network analyzer and de-embedding the device S-parameters.

\section{Experimental Results}

The light generated voltage, $v_{1 j t}$, is obtained by plotting the measured gate current $I_{g}$ as a function of the reverse biased gate to source voltage $V_{g s}$, and extrapolating the graph until it intersects the $X$-axis. The 
intersection point is read as the light generated voltage, which from figure 6 for a AlGaAs/GaAs HEMT is $0.57 \mathrm{~V}$. An experiment was conducted by illuminating the HEMT device with an optical signal which had been modulated with a $8 \mathrm{GHz}$ RF signal. The detected $8 \mathrm{GHz}$ output was observed on a spectrum analyzer and is shown in figure 7. For the purpose of displaying on a spectrum analyzer and external amplifier with a gain of $20 \mathrm{~dB}$ was added. The HEMT has a responsivity of $3.53 \mathrm{~A} / \mathrm{W}$ with $\mathrm{V}_{\mathrm{gs}}=-0.55$ and $V_{\mathrm{ds}}=3.0 \mathrm{~V}$.

\section{MONOLITHIC INTEGRATION OF MICROWAVE AND OPTICAL FUNCTIONS}

In the past several years, GaAs substrates have provided the basis for the development of monolithic microwave integrated circuit technology. Low loss microstrip lines can be fabricated on this semi-insulating substrate. The high electron saturation velocity provides the essential microwave device integration of both optical and microwave functions for advanced circuit applications (ref. 13). This quality is attractive for optically controlled phased array antenna applications in space communications to provide low weight and reduced complexity systems. The optical fiber can be coupled through an aligner to an integrated photodetector on a GaAs monolithic microwave integrated circuit (MMIC). It is shown here that optically controlled microwave device structures (interdigitated photodetector) can demodulate an RF signal carried via an optical signal. It can also detect and amplify a gigabit digital signal or an analog signal to control phase shifter and amplifier gain functions in an MMIC transmit module. An optical integrated circuit which will control the phase shifting and amplifier gain function of an MMIC transmit module is being fabricated by Honeywell, Inc. for the NASA Lewis Research Center (ref. 14). In a MESFET process, Wojtczuk i.e. (ref. 15) have fabricated a monolithically integrated photoreceiver to illustrate the feasibility and ease of integrating these detectors.

\section{CONCLUSIONS}

It is well known that HEMT devices have an advantage over the GaAs MESFET because of the higher electron mobility in undoped GaAs layer compared to the doped GaAs used in GaAs MESFETS. However, in case of photodetectors discussed in this paper, the main advantage observed is the higher absorption thickness ( $1 \mu \mathrm{m}$ GaAs) avallable in the HEMT structures which increases gain and coupling efficiency. Due to trapping of the holes in the substrate, the optical response showed slow tail ( $f i g .5(a)$ ). It is possible to design a structure where the minority carriers that is the holes can be "picked".

\section{ACKNOWLEDGMENT}

One of us (K. Bhasin) is thankful to Professor L.F. Eastman, R.G. Wicks, and $\mathrm{Mr}$. D.C. Radulescu from Cornell University for their support and encouragement. 


\section{REFERENCES}

1. Bhasin, K.B., Anzic, G., Kunath, R.R., and Connolly, D.J., "Optical Techniques to Feed and Control GaAs MMIC Modules for Phased Array Antenna Applications," in 11th AIAA Communications Satellite Systems Conference, AIAA, New York, pp. 506-514, 1986.

2. de Salles, A.A.A., "Optical Control of GaAs MESFET's;" IEEE Trans. Microwave Theory Tech., Vol. 31, pp. 812-820, 1983.

3. Forrest, J.R., Richards, F.P., and Perichon, A., "The Microwave MESFET Optical Detector," in IEDM Technical Digest 1982, IEEE, New York, pp. 529-532, 1982.

4. Baack, C., Elze, G., and Wolf, G., "GaAs M.E.S.F.E.T.: A High-Speed Optical Detector," Electron. Lett., Vol. 13, p. 193, 1977.

5. Gammel, J.C., and Ballantyne, J.M., "The OPFET: A New High Speed Optical Detector," in IEDM Technical Digest 1978, IEEE, New York, pp. 120-123, 1978.

6. Gautier, J.L., Pasquet, D., and Pouvi1, P., "Optical Effects on the Static and Dynamic Characteristics of a GaAs MESFET," IEEE Trans. Microwave Theory Tech., Vol. 33, pp. 819-822, 1985.

7. Slayman, C.W., and Figueroa, L., "Frequency and Pulse Response of a Novel High Speed Interdigital Surface Photoconductor (IDPC)," IEEE Electron Device Lett., Vol. 2, pp. 112-114, 1981.

8. Roth, W., Schumacher, H., Kluge, J., Geelen, H.J., and Beneking, H., "The DSI Diode - A Fast Large-Area Optoelectronic Detector," IEEE Trans. Electron Dev., Vol. 32, pp. 1034-1036, 1985.

9. Simons, R.N., and Bhasin, K.B., "Microwave Performance of an Optically Controlled AlGaAs/GaAs High Electron Mobility Transistor and GaAs MESFET," in IEEE-MTTS International Microwave Symposium Digest. IEEE, New York, pp. 815-818, 1987.

10. Chen, C.Y., Cho, A.Y., Bethea, C.G., Garbinski, P.A., Pay, Y.M., Levine, B.F., and Ogawa, K., "Ultrahigh Speed Modulation-Doped Heterostructure Field-Effect Photodetectors," Appl. Phys. Lett., Vol. 42, pp. 1040-1042, 1983.

11. Umeda, T., Cho, Y., and Shibatomi, A., "Picosecond HEMT Photodetector," Jpn. J. Appl. Phys. Lett., Vol. 25, pp. L801-L803, 1986.

12. Darling, R.B., "Transit-Time Photoconductivity in High-Fleld FET Channels," IEEE Trans. Electron Devices, Vol. 34, pp. 433-444, 1987.

13. Hunsperger, R.G., "Optical Control of Microwave Devices," in Integrated Optical Circuit Engineering II, Proc. SPIE Vo1. 578, S. Sriram, ed., SPIE, Bellingham, WA, pp. 40-45, 1985. 
14. Bhasin, K.B., and Connolly, D.J., "Advances in Gallium Arsenide Monolithic Microwave Integrated Circuit-Technology for Space Communications Systems," IEEE Trans. Microwave Theory Tech., Vol. 34, pp. 994-1001, 1986.

15. Wojtczuk, S.J., Ballantyne, J.M., Chen, Y.K., and Wanuga, S., "Monolithically Integrated Photoreceiver With Large Gain-Bandwidth Product," Electron. Lett., Vol. 23, pp. 574-576, 1987.

\section{INCIDENT LIGHT BEAM}

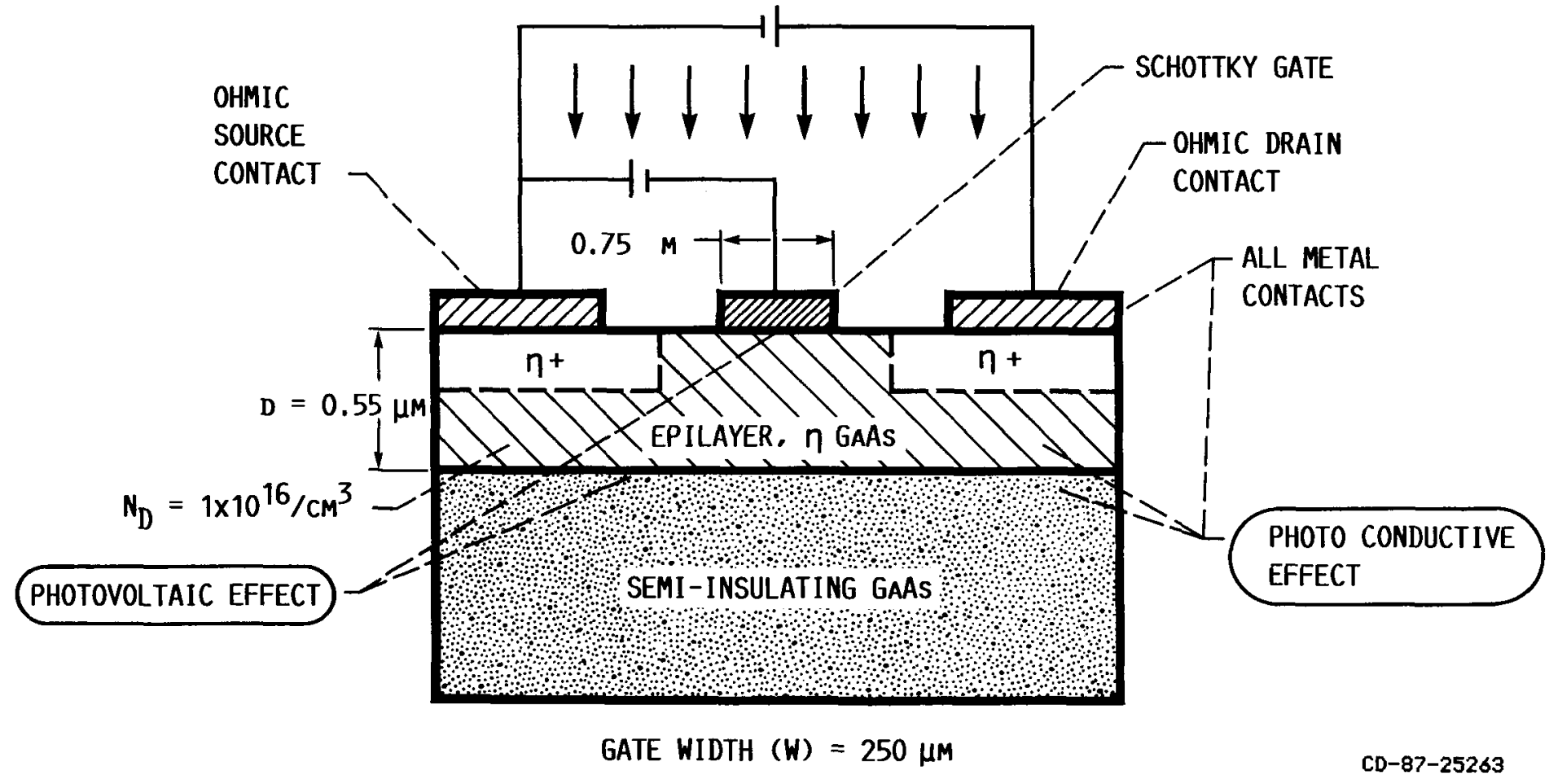

FIGURE 1. - PHYSICAL MECHANISM OF AN OPTICALLY CONTROLLED MESFET. 


\section{ORIGINAL PAQE IS \\ OF POOR QUALITY}

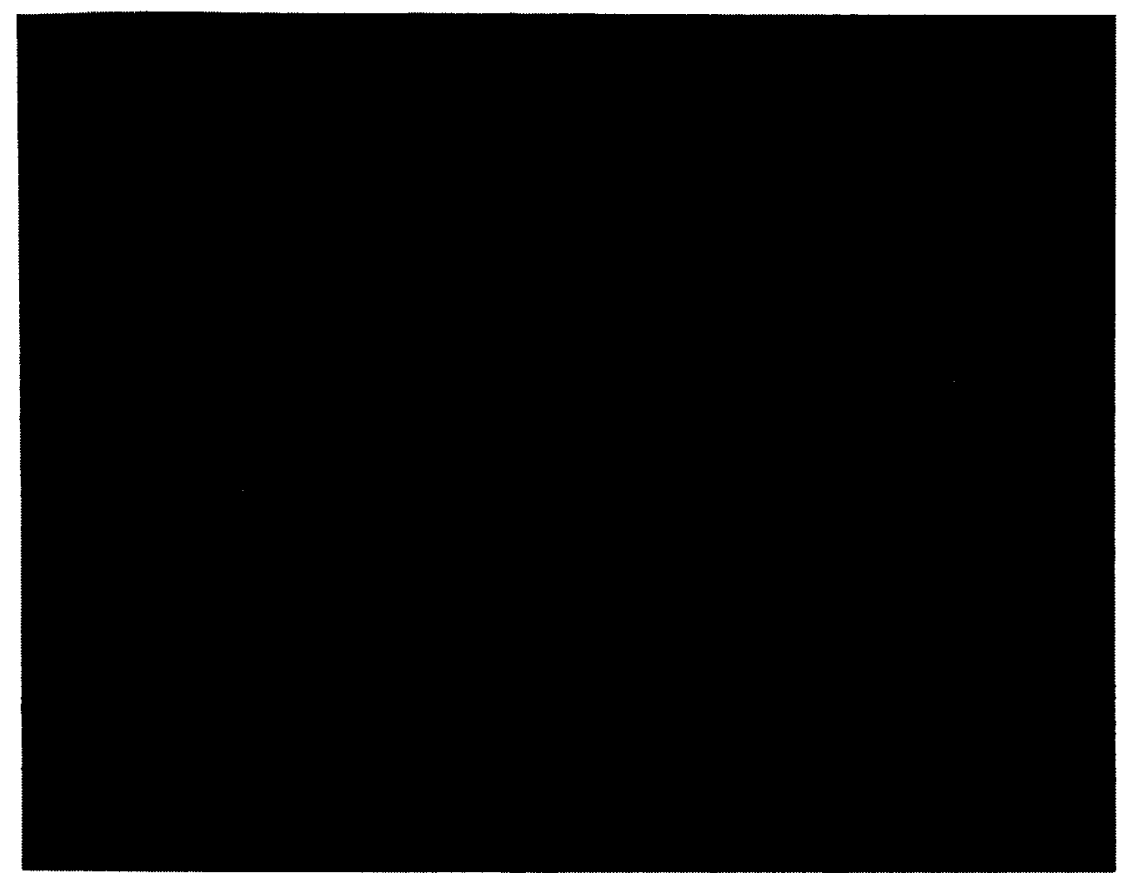

FIGURE 2. - $50 \mu \mathrm{M} \times 50 \mu \mathrm{M}$. INTERDIGITATED PHOTO CONDUCTIVE DETECTOR.

HEMT PHOTOCONDUCTOR STRUCTURE

\begin{tabular}{|c|c|c|c|}
\hline \multirow[t]{6}{*}{$\begin{array}{c}\mathrm{Au} / \mathrm{Ge} / \mathrm{Ni} \\
\text { OHOMIC CONTACT }\end{array}$} & & \multicolumn{2}{|c|}{$\begin{array}{c}\mathrm{Au} / \mathrm{Ge} / \mathrm{Ni} \\
\text { OHOMIC CONTACT }\end{array}$} \\
\hline & & $\begin{array}{c}\text { GaAS } \\
\text { (Si } 1 \text { Ex18) }\end{array}$ & $400 \mathrm{~A}$ \\
\hline & \multicolumn{2}{|l|}{ GaAlAs (Si2x1Ex18) } & $400 \mathrm{~A}$ \\
\hline & \multicolumn{2}{|l|}{ GaAIAS SPACER } & $40 \mathrm{~A}$ \\
\hline & \multicolumn{2}{|l|}{ GaAs ( < Ex15) } & $1.2 \mu \mathrm{M}$ \\
\hline & S. I. GaAs & & \\
\hline
\end{tabular}

FIGURE 3. - VERTICAL MATERIAL STRUCTURE OF HEMT PHOTOCONDUCTOR. 


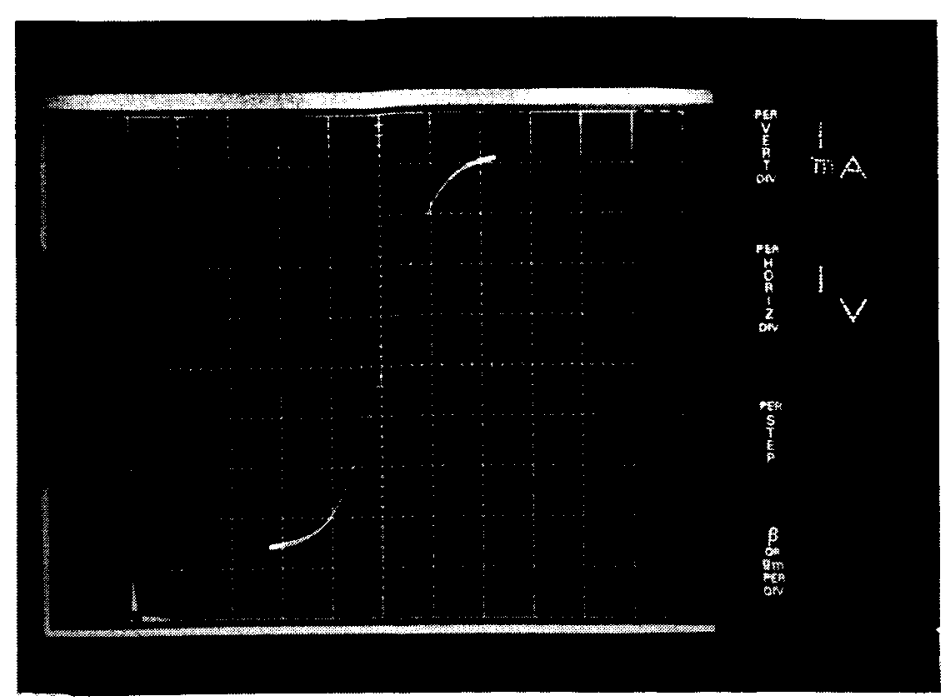

FIGURE 4. - I-V CURVE OF HEMT PHOTOCONDUCTOR. VERTICLE: 1 MA/DIV, HORIZONTAL; 1V/DIV.
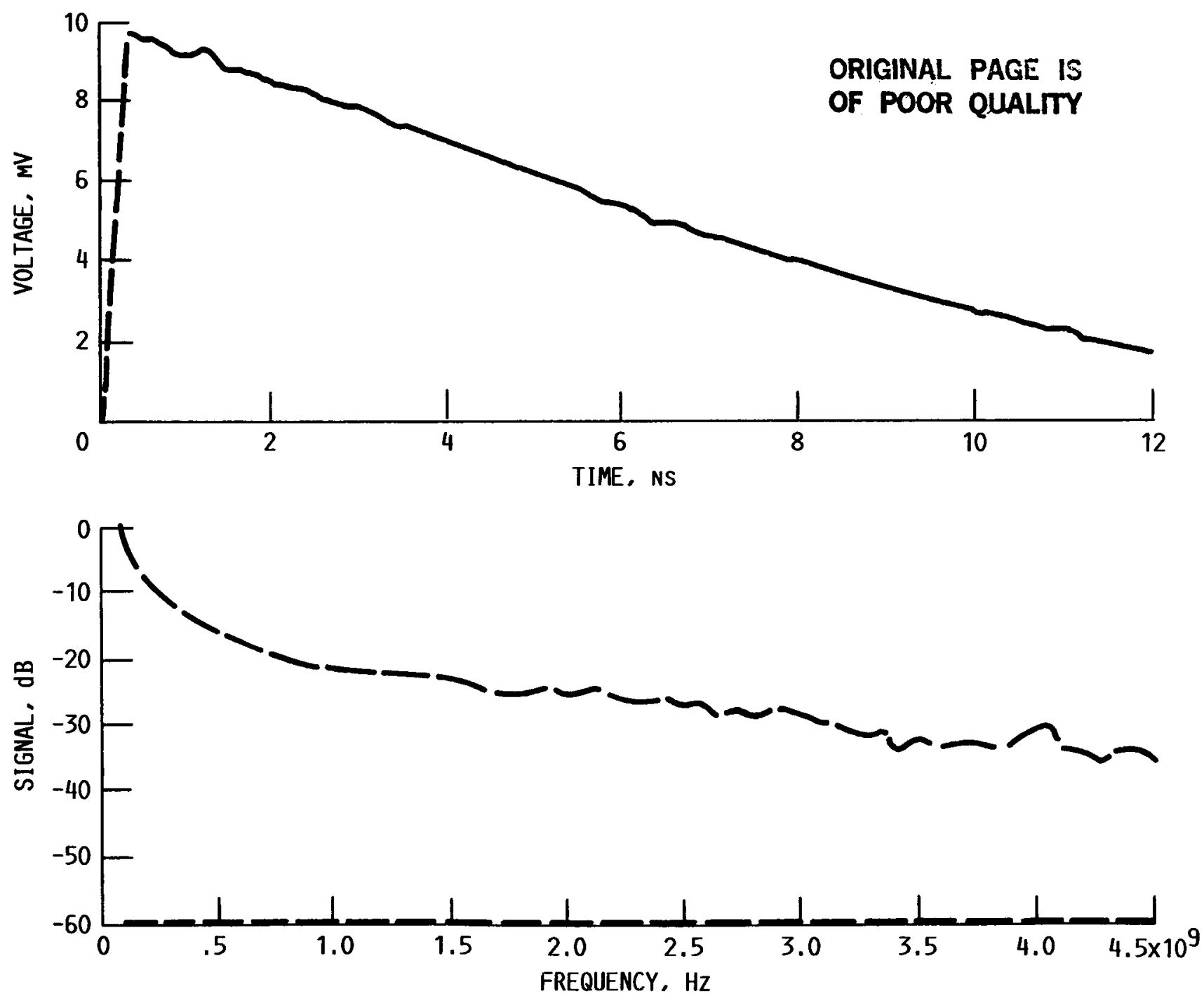

FIGURE 5. - TIME (A) AND FREQUENCY RESPONSE (B) OF AN HEMT PHOTOCONDUCTOR. 


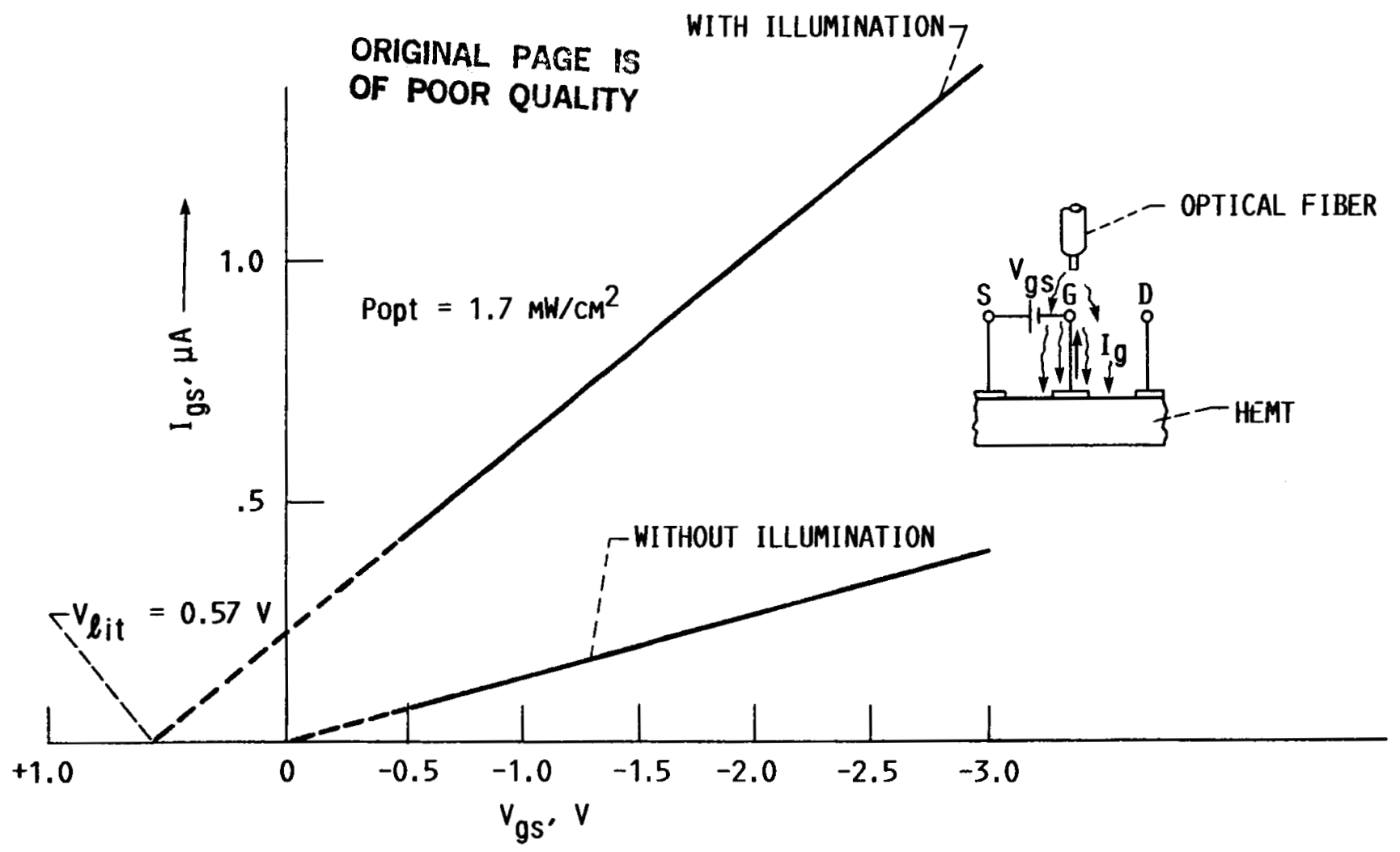

FIGURE 6. - MEASURED GATE CURRENT ( $\left.I_{G}\right)$ VERSUS GATE TO SOURCE VOLTAGE $\left(V_{G S}\right)$. DRAIN IS KEPT OPEN. DISTANCE BETWEEN END OF FIBER AND DEVICE IS $1 \mathrm{mM.}$

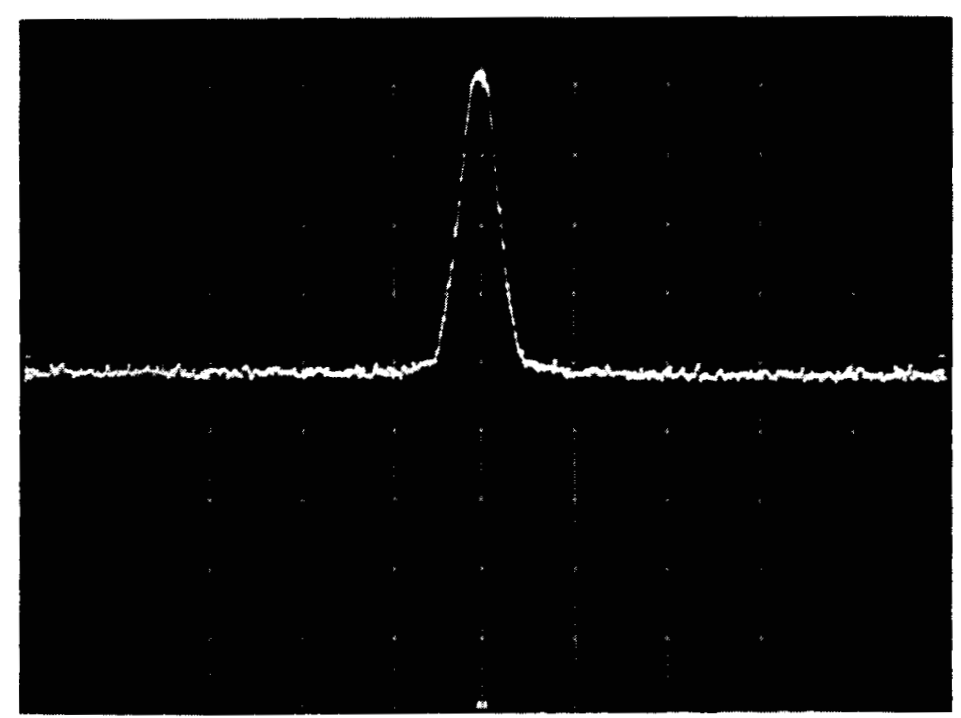

FIGURE 7. - DETECTED $8 \mathrm{GHZ}$ SIGNAL. 


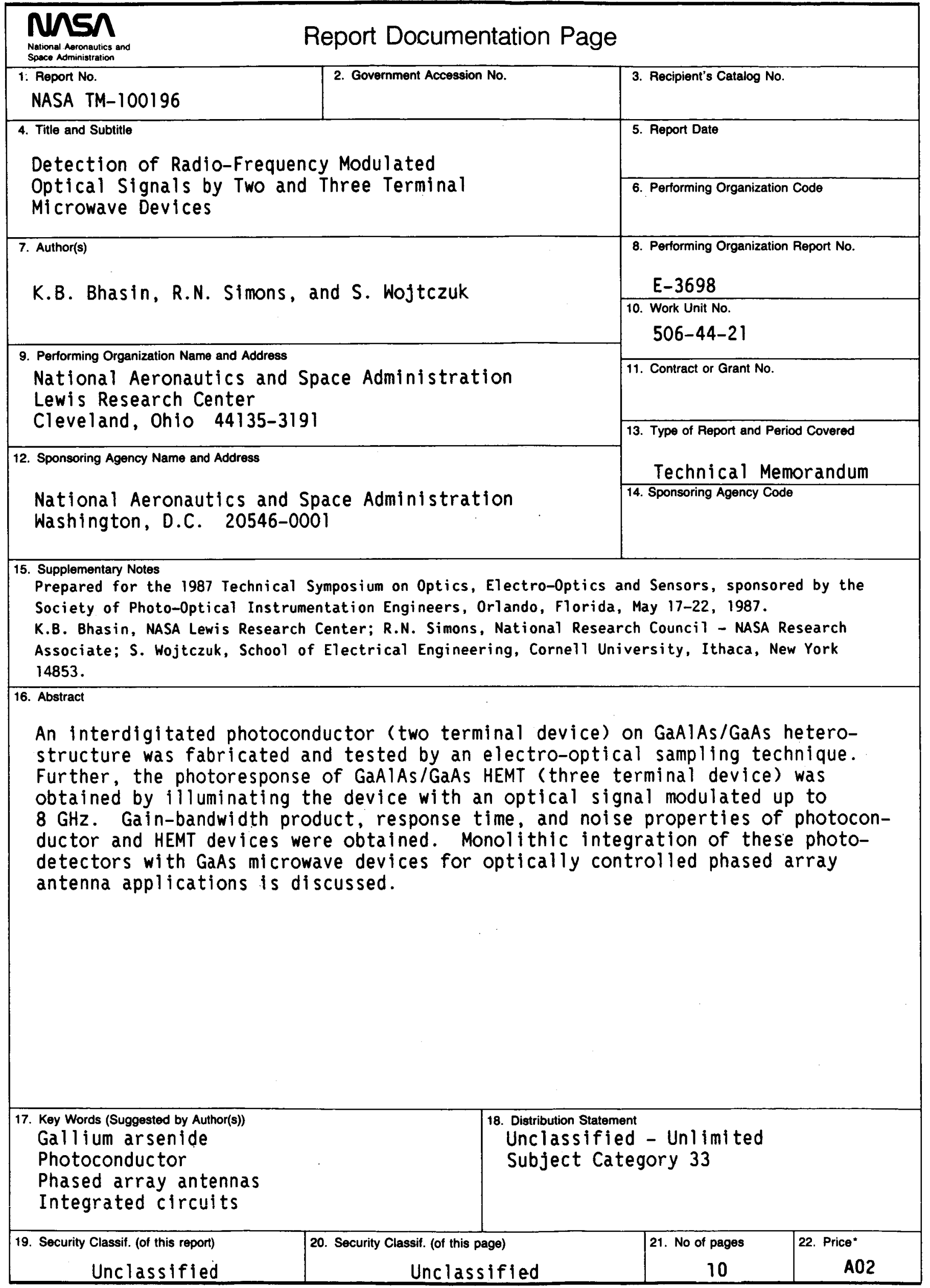

NASA FORM 1626 OCT $86 \quad$ "For sale by the National Technical Information Service, Springfield, Virginia 22161 